\section{La licencia médica. Varias dimensiones en un mismo documento. Una propuesta para un mejor uso}

\author{
MAURICIO BESIO
}

\section{A proposal to improve sick leaves granted by physicians}

From time to time, sick leaves granted by physicians, cause concern among professionals, patients and institutions that administer the funds required to finance the days of work. This document analyzes different aspects of the form that must be filled by the physician to grant the sick leave, reflects on some important difficulties that are faced by health care professionals to complete the document and proposes changes to the form to correct such difficulties. Also, a proposal for a fairest solution for professionals and patients is presented.

(Rev Med Chile 2011; 139: 1503-1507).

Key words: Ethics, medical; Medical; Philosophy; Sick leave.

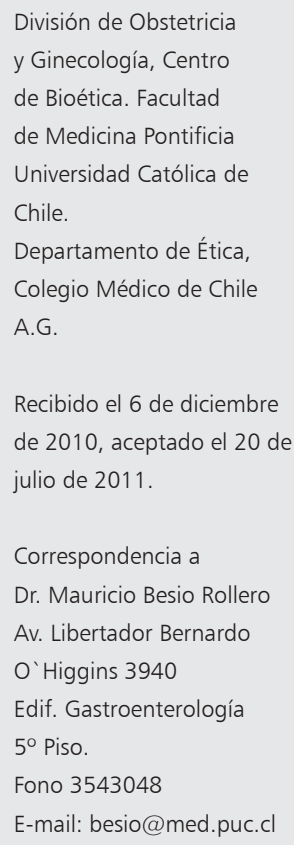

C ada cierto tiempo irrumpen en los medios de comunicación noticias referentes al supuesto mal uso que pacientes y médicos estarían dando al documento denominado "licencia médica", causando la correspondiente alarma tanto en las instituciones responsables de entregar los fondos destinados a cancelarlas como en los organismos encargados de su fiscalización, y también en el Colegio Médico de Chile, que debe velar por un adecuado actuar de sus colegiados. Los distintos involucrados se sienten legítimamente afectados: los pacientes al necesitar contar con un mecanismo que les permita un tratamiento médico sin ser perjudicados laboralmente, los médicos cuando se pretende limitar o condicionar un acto que consideran legítimo y parte constitutiva de su profesión, y los proveedores de los fondos porque, al poseer la extensión de este certificado un efecto económico para ellos, se perciben también como interlocutores válidos en la discusión.

El tema causa naturalmente preocupación social, ya que la manera de enfrentar los derechos de los trabajadores en lo que a salud se refiere, es en definitiva un problema que nos involucra a todos como sociedad. En consecuencia y como partes de ella, a las instituciones que agrupan a médicos también les corresponde opinar acerca de las dificultades que conllevan las licencias médicas, para poder así diseñar una estrategia que logre una disminución de los conflictos que genera. Parece necesario entonces iniciar una reflexión y elaborar propuestas al respecto. Este artículo busca precisamente estos dos objetivos, dejando para otra oportunidad un análisis ético sobre el uso o abuso de las licencias.

\section{Concepto y alcances de la licencia médica}

Cuando hablamos de una licencia médica, nos referimos a un documento en el que se certifica -alguien con autoridad para ello-, que un sujeto debe cumplir reposo por indicación médica, que en el caso de un trabajador implica ausentarse parcial o completamente de su jornada laboral sin perder por eso sus derechos y salarios. Este reposo no debe entenderse solamente en su connotación física, como pudiera ser el originado por un traumatismo u enfermedad orgánica, ya que es perfectamente posible que se le indique por un trastorno psicosomático, del ánimo, o definitivamente mental. Se trata entonces de un documento 
que surge de una indicación clínica y tiene un origen de esa índole. Es el médico -u odontólogo- quien juzga el momento en que su paciente requiere, como parte de una terapia, un reposo que puede ser absoluto, relativo o parcial. Tiene entonces el mismo estatuto que la indicación de un antibiótico, una quimioterapia o una cirugía, y es prerrogativa sólo del clínico tratante juzgar acerca de su entrega. Recordemos que las matronas, aun cuando también pueden extenderla, limitan su entrega sólo a las que determinan el reposo pre y postnatal ${ }^{1}$. Es por ello, que nos referiremos en este trabajo sólo a las extendidas por clínicos.

Es necesario precisar dos aspectos que pueden generar aquí alguna dificultad. El primero se refiere al reposo preventivo. Así como el médico muchas veces establece para su paciente alguna intervención que no busca la curación de una enfermedad sino que la prevención de ella, es perfectamente posible que indique reposo a un paciente también como medida preventiva. Ocurre esto por ejemplo en embarazos de mayor riesgo, en situaciones laborales con exposición a contaminantes, en cambios de circunstancias laborales en pacientes con patologías crónicas y otros. Si bien es cierto esto no es muy frecuente, es necesario dejar establecida la legitimidad de este acto, y no es de ninguna manera aceptable que se cuestione a un médico por la indicación de reposo preventivo.

El segundo aspecto es la dificultad para definir enfermedad o salud. Si nos atenemos a la definición de la OMS, cual es: "Salud es el estado de completo bienestar físico, mental y social y no la mera ausencia de enfermedad...."2, cualquier "discomfort" puede constituir una enfermedad. Siendo esta concepción bastante complicada para los efectos de determinar la licitud de una licencia médica, ya que incorpora al concepto de enfermedad, situaciones que por lo menos originalmente, no se derivan del concepto intuitivo de patología. A veces se presentan alteraciones en la salud de pacientes provocadas por trastornos laborales, familiares o sociales. Si bien es cierto existen conflictos relativos a estos ítems que debieran resolverse en instancias ajenas a una licencia médica, como pueden ser los tribunales del trabajo o asistencias sociales, sucede que sí podrían provocar una consecuencia que es susceptible de requerir -preventiva o curativamente- un reposo, $\mathrm{y}$ es absolutamente legítimo que un médico lo pueda indicar.

\section{Licencia y acto médico}

La licencia médica es entonces, en su primera dimensión, parte del acto médico. La indicación del reposo es absolutamente prerrogativa del médico u odontólogo y ese hecho no puede ser bajo ningún aspecto vulnerado. Intentarlo no puede ni debe ser permitido por ninguna agrupación médica. El clínico es el que propone a su paciente esa precisa medida terapéutica, que el paciente puede o no aceptar, al igual que cualquier otra indicación.

Además de ser una legítima acción médica, la licencia tiene una segunda dimensión. Es un documento extendido por un profesional que actúa como ministro de fe, esto para certificar a otras instituciones -laborales o judiciales- que una persona ha faltado o faltará a su trabajo por razones de salud. Son los médicos cirujanos o cirujanos dentistas a los únicos a quienes la sociedad les ha entregado esta responsabilidad, y ningún trabajador puede ser despedido si presenta este certificado bajo las condiciones establecidas por la ley.

Este documento tiene, por último, una tercera dimensión. Mediante este certificado, el trabajador recibe, a cargo de lo impuesto por él mismo mensualmente a alguna institución o fondo de salud previsional, una remuneración similar a la que recibiría si estuviese trabajando. Es justamente esta última dimensión la que más conflictos provoca, porque involucra a los médicos en un área que no tiene relación directa con los objetivos de la medicina (prevención de enfermedad, mantenimiento de la salud, alivio del dolor y del sufrimiento, asistencia y curación de los enfermos, el cuidado de los que no pueden ser curados, el evitar la muerte prematura y el velar por una muerte en paz) $)^{3,4}$, esto porque la sociedad les demanda peritajes, contralorías médicas y la certificación de otros muchos hechos.

Es únicamente su primera dimensión la que tiene relación con la medicina clínica, porque el reposo es una indicación propiamente médica, extender una licencia es un acto médico con toda propiedad. Tanto la segunda como la última dimensión, están en el ámbito de las responsabilidades de la sociedad, pero ésta, sin embargo, se las pide a los médicos, y así es que nos vemos participando incluso en la transferencia de recursos económicos que afectan a las entidades financieras de salud y a los propios trabajadores.

Como profesionales, naturalmente entende- 
mos y aceptamos nuestras responsabilidades sociales, como el actuar de ministros de fe, sin embargo, es legítimo que intentemos también delimitar y jerarquizar, entre todos los aspectos de nuestro ejercicio profesional, cuáles son a los que nos debemos con un imperativo ético y secundariamente a cuáles debemos responder por ser árbitros o mediadores. No olvidemos que el cumplimiento o incumplimiento de esta última labor trae consigo también intentos de desprestigio a la profesión, por conflictos que primariamente deberían ser resueltos entre los trabajadores y otras entidades. Como médicos tratantes, también nos interesa esa discusión o mediación, pues no nos son indiferentes las condiciones en que un trabajador realice su reposo, esto es con la tranquilidad o intranquilidad de contar con el justo beneficio económico. Mas, a diferencia del reposo como indicación médica que sí nos concierne directamente, nuestra postura aquí es una más de los varios participantes con derecho de opinión.

Por tanto, debemos entonces buscar una fórmula que, conjugando adecuadamente las tres distintas dimensiones de la licencia médica, permita salvarlas y jerarquizarlas con justicia, entregando y devolviendo al médico a su quehacer primero, al paciente la tranquilidad de la justa protección y a la sociedad su papel garante; fórmula que necesita para su éxito, la participación responsable de los tres involucrados: el médico, el trabajador y las entidades administradoras de los fondos de salud.

\section{Propuesta}

Parece muy adecuado en una relación médicopaciente participativa, que el reposo sea entendido como cualquier intervención médica. El médico y el paciente ponderan los beneficios y los costos que su implementación conlleva, y dependiendo de esa evaluación, la reconsideran; a veces el reposo propuesto por el médico es rechazado o limitado por el paciente, porque no le gusta faltar a sus deberes laborales o teme una mala evaluación de sus empleadores. Se resiste entonces a la indicación de una licencia y solicita al médico una solución alternativa, que éste debe considerar. En estos casos es el paciente el que evalúa como de un alto costo faltar a su trabajo. En la mayoría de los casos sin embargo, el paciente acepta el reposo con alivio y entiende que es parte de su tratamiento, y pone en él la misma esperanza de curación que pone en todas las otras intervenciones implementadas.

Actualmente, al presentársele al clínico el tener que juzgar sobre la necesidad de otorgar una licencia de manera preventiva o por una situación que afecta a un paciente y que es derivada de conflictos laborales o sociales, lo debe hacer en un documento que simultáneamente tiene las tres connotaciones: clínica, certificación laboral y entrega de subsidios. Frecuentemente por tanto, corre el riesgo de actuar injustamente. En efecto, si se apega estrictamente a extender una licencia sólo como parte de un tratamiento de una patología típica que requiere reposo, difícilmente la extenderá para prevenir una enfermedad sólo probable, y nunca para solucionar un problema social, como pudiera ser la necesidad angustiosa de cuidar un hijo. Este tratante sabe perfectamente que extender el documento significa no sólo que el paciente tiene justificada su inasistencia laboral, sino que alguna institución deberá pagar el subsidio, por lo que tenderá a ser estricto en su otorgamiento. Su manera de proceder, podría arriesgar la salud futura de su paciente o aumentar su angustia al no poder cuidar a su hijo, siendo que lo único que quiere es que no lo despidan por inasistencia. Como contraparte, sería injusto para las entidades que deben entregar subsidios por enfermedad, hacerse cargo de financiar las ausencias laborales por razones ajenas a un cuadro patológico típico y delimitado, aun cuando puedan constituir perfectamente una patología según la amplia definición de salud de la OMS.

Atendiendo a todo lo expuesto, me atrevo a proponer establecer un documento de licencia médica que posea, además de las alternativas de reposo que ya existen (total y parcial), las siguientes:

\section{Reposo médico por razones curativas}

Es el reposo médico propiamente tal, aquel indicado como terapia de una patología concreta y típica, cuya recuperación o rehabilitación debe pasar necesariamente por un período de baja actividad física y bajas exigencias mentales o psicológicas. La extensión de este reposo debe ser lo establecido por las guías clínicas, conocidas y aceptadas por cada especialidad médica. Cualquier extensión más allá de esos límites, por razones relacionadas con la peculiaridad de un paciente en particular, deberá ser justificada por el médico tratante. 
Durante este reposo el trabajador deberá recibir su remuneración completa por cada uno de los días que falte a sus labores.

\section{Reposo médico por razones preventivas}

Es aquel otorgado por alguna condición del paciente que, sin constituir una patología concreta actual, significa un riesgo de salud para él. Aquí se pueden invocar situaciones laborales que, siendo comunes, pueden ser potencialmente dañinas en un momento o situación dado; como ejemplos, carecer de un estado de salud completo, cursar un embarazo o sufrir una discapacidad.

Se entiende que en estas situaciones el médico considera que hay un riesgo potencial de daño en salud, sin tener la completa certeza de ello, y la razón por la que se otorga esta licencia es evitarlo o minimizarlo. El paciente, si acepta la licencia, deberá aceptar también que el subsidio que recibirá pudiera ser menor que su remuneración completa, ya que la licencia pretende sólo evitar un riesgo y no es parte del tratamiento de una enfermedad.

\section{Reposo por razones psico-sociales}

Es aquella licencia médica entregada en aquellas situaciones que provocan en el paciente un estado de angustia tal que la requiere como única solución a su problema. Estos estados de angustia, aunque reactivos, pueden ser considerados como una alteración de salud, y su etiología es el no poder faltar al trabajo para solucionar algún problema que requiere su presencia; como pudiera ser cuidar a un hijo o familiar enfermo.

Parece razonable que se permita eliminar la causa que condiciona la alteración de salud mediante el permiso para faltar a sus labores sin ser despedido. Sin embargo, es muy razonable también que el afectado reciba un porcentaje bastante menor del total de su remuneración, ya que la causa del problema de salud no es del ámbito sanitario sino laboral o social.

El médico deberá evaluar el real estado anímico del paciente y éste deberá ponderar los beneficios y pérdidas que obtendrá con la licencia para aceptarla o rechazarla.

\section{Conclusión}

La complejidad del paciente como sujeto personal hace insuficiente la consideración de la enfermedad como un daño sólo funcional u orgánico. Las enfermedades psico-somáticas y los trastornos reactivos son ejemplos de una medicina que no se agota en intervenciones curativas. Por otro lado, las acciones de prevención y de rehabilitación constituyen parte importante de la responsabilidad del médico, y es perfectamente posible entonces que éste extienda una licencia a un paciente sin una patología actual, captando que su actividad laboral puede constituirse en un riesgo de salud.

El documento "licencia médica" utilizado actualmente en nuestro país no permite dar cuenta de esta complejidad. Además, el hecho de que actualmente se promueve una participación responsable y activa tanto de médicos como pacientes en las decisiones de salud, ha llevado a generar esta propuesta de un cambio en este documento, cambio conducente a reconocer los distintos aspectos de una licencia médica, distinguir las muchas y diferentes situaciones de salud y promover asimismo la participación responsable en este tema de los médicos, pacientes e instituciones de salud provisional, delimitando en cada uno de estos actores el campo de responsabilidad que les corresponde.

Los médicos y los pacientes debemos asumir la licencia médica con la misma responsabilidad que cualquier otra indicación médica, dando y otorgando información y ponderando efectos beneficiosos y adversos. Los empleadores e instituciones de salud previsional deben, asimismo, respetar absolutamente el mandato otorgado a los médicos como ministros de fe, aceptando el fuero por reposo médico y cumpliendo con la entrega de los fondos que pertenecen a los trabajadores.

En la licencia médica, aún cuando convergen varios propósitos, lo esencial es la indicación de reposo para un paciente, y esto por parte de un médico en su rol de experto, con validación legal y social para fines de protección laboral. Si el médico actúa como ministro de fe dentro de la sociedad, el intentar cuestionar o alterar sus indicaciones no debe ser permitido bajo ningún aspecto por ninguna agrupación que defienda a la profesión médica.

El desempeño de un médico exige que este profesional posea un comportamiento ético ejemplar, por lo tanto, nada puede justificar que cometa acciones ilícitas que, además, desprestigien la profesión. 
La licencia médica. Propuesta para mejor uso - M. Besio

En el tema de las licencias médicas, excepcionalmente se acusa a profesionales de la salud por extenderlas de manera fraudulenta. Ese hecho es y debe ser siempre condenado y sancionado tanto por la sociedad como por las agrupaciones médicas.

\section{Referencias}

1. Reglamento de autorización de licencias médicas por las compin e instituciones de salud previsional, art. 6 . Consultado el 30 de noviembre 2009. Disponible en:
http://www.leychile.cl/N?i=7281\&f=2006-03-16\&p=

2. Preamble to the Constitution of the World Health Organization as adopted by the International Health Conference, New York, 19-22 June, 1946; signed on 22 July 1946 by the representatives of 61 States (Official Records of the World Health Organization, no. 2, p. 100) and entered into force on 7 April 1948. Consultado el 30 de noviembre 2009. Disponible en: http://who.int/ about/definition/en/print.html

3. Besio M. Sobre el acto médico. Cuadernos de Bioética 2003; Vol. XIV No 50 1a: 25-38.

4. The Goals of Medicine: Setting New Priorities Hastings Center Report 26, no. 6 (1996). 